\title{
The influence of the chromatic effect of crispening on the shift in the manifestation of the color of the observer
}

\author{
Petra Bradić', Krunoslav Hajdek', Mile Matijević ${ }^{2}$, Martina Hajdek \\ 'University North, University center Varaždin, 104. brigade 3., 42000 Varaždin, Croatia \\ 2Faculty of Graphic Arts, University of Zagreb, Getaldićeva ulica 2, 10000 Zagreb, Croatia \\ ${ }^{3}$ Grafički zavod Hrvatske, Mičevečka ulica 7, 10000 Zagreb, Croatia
}

\begin{abstract}
The paper presents the results of the research on the manifestation of the chromatic effect crispening, where the primary stimuli are designed as squares in the blue-green color with the values of 55\% RTV and 65\% RTV, while the secondary stimuli are designed as backgrounds in the purple color and their variations are made in the values of $25 \%$ RTV, $50 \%$ RTV, 75\% RTV and $100 \%$ RTV that surrounds the primary stimuli. Ten respondents of both sexes participated in the research. They had the task to match on a computer screen through the binocular harmonization technique the test primary stimuli with the referential stimuli, so that the test primary stimuli are perceived the same or equal to the referential primary stimuli. The intensity of the effect was determined and presented in the CIEDE00 system. The results of the research show that the intensity of the effect was more pronounced on the test primary stimuli of $65 \% \mathrm{RTV}$, where the deviations in the perception of color were more pronounced. The smallest deviation was measured on the primary stimulus of 55\% RTV with the background of $75 \%$ RTV, which is also a recommendation to the designers when creating a conceptual solution with the combination of pairs presented in this paper.
\end{abstract}

Keywords: crispening effect, perception, shift in the manifestation of color, visual psychophysics

\section{Introduction}

Nowadays, visual effects are being increasingly used in design. As the market is highly competitive in offering a variety of products, and as it is known that packaging or advertising that makes a product successful or less successful greatly influences the consumer, designers have resorted to the use (deliberately or unintentionally) of certain conceptual solutions in order to "alienate" the product for whose advertising they are in charge of from other products on the market. Their goal is to create such a conceptual solution of the final product that will instantly attract the consumer's attention and create his/her desire for its consumption.

The manifestation of psychophysical visual effects is largely undesirable, especially that of the background visual effects which in the cross-media reproduction system cause unwanted and unexpected manifestations of the intended conceptual solution of the finished product.

Background effects are divided into simultaneous contrast, spreading and crispening, and specifically the aforementioned effects, depending on the design solution, can be manifested as achromatic, chromatic or desaturated. The papers $[1,2]$ describe how the achromatic design solution prompts the manifestation of the background effect of simultaneous contrast, while in the papers of the authors Vusić et.al. [3] it is shown how the neon color spreading effect affects the manifestation of color.

The psychophysical visual effect of crispening is defined as an increase in the intensity of 
color perception between the stimuli of two colors that are being mutually compared [4], and in this paper it will be shown how the effect of crispening with certain pairs of colors (purple and blue-green) affects the perception of the observer, while in the paper of the authors Hajdek et al. [5] it is shown how the effect of crispening with the change in background lightness affects the respondents.

The scientist Takasaki was the first who discovered and gave the name to the crispening effect, and he described it in his papers from 1966 and 1967 [6, 7]. In those papers he explained how the change in color and background lightness influences the manifestation of the effect.

Following Takasaki's research, the scientist Semmerloth found a model that proves the quantitatively adequate explanation of Takasaki's crispening effect [8].

In their 2017 research, scientists Karimipour and Gorji conclude the following: "According to the results of a comparative test, the crispening intensifies when two stimuli have just lightness difference instead of just chromaticity difference" [9]. Furthermore, scientists Kane and Bertamlio examine in their paper the perception of light and the manifestation of the crispening effect with the help of five different variations of background lightness from $0 \%$ to $100 \%$ of illumination, and they analyze the perception of light and the evaluation of contrast [10].

When analyzing the manifestation of the crispening effect, the aim is always to determine how different changes in the lightness and color of the background influence the perception of the observer, and to determine the degree of deviation of the same pattern which causes the manifestation of the crispening effect and which is shown on different media. With that aim in mind, it was tried in advance with the help of certain formulas to determine how strong the crispening effect will be regarding the change in the background lightness [11, 12].

The aim of each psychophysical visual research is to determine in what way certain parameters and to which degree their change affects the respondent's perception of perceptual attributes and their colorimetric differences. In this paper, it will be determined how great the shift in color is during the manifestation of the chromatic effect of crispening with the selected pairs of the color of the primary and secondary stimuli, all with the aim of predicting the intensity of the effect presented on a particular medium.

\section{Experimental part}

In the experimental part of the research, samples that cause the manifestation of the crispening effect were made. The samples were made as chromatic in the following way: as a secondary stimulus (background), a square painted in the purple color was made; while for the primary stimulus (inner square), the blue-green color was used. Four fields of secondary stimuli with the initial secondary stimulus with the value of $25 \%$ RTV were made, and each subsequent secondary stimulus was increased by $25 \%$ RTV (25\% RTV, 50\% RTV 75\% RTV and 100\% RTV). Within that rectangle, there are two smaller rectangles (primary stimuli) painted in the blue-green color with the value of 55\% RTV for the left field and of $65 \%$ RTV for the right field (Figures 1 to 4 ). The sample is considered to be referential, and below the referential sample there was a test sample with the secondary stimulus with a certain value (25\% RTV, 50\% RTV, 75\% RTV and 100\% RTV) and the blank fields of the primary stimuli, in which the respondents were supposed to enter the harmonized values of the primary stimuli in order for the primary stimuli to be the same or as similar as possible to the referential primary stimuli.

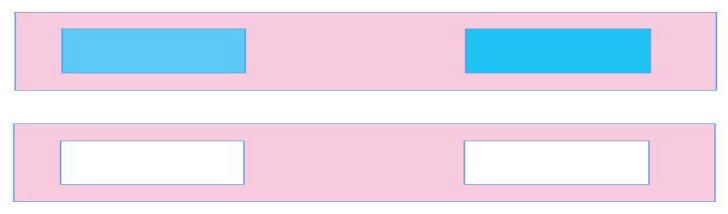

Figure 1. Test sample of the crispening effect with the secondary stimulus of $25 \%$ RTV and the primary stimuli of $55 \%$ RTV(left) and $65 \%$ RTV (right)

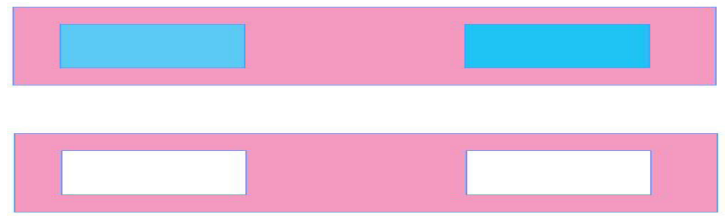

Figure 2. Test sample of the crispening effect with the secondary stimulus of $50 \%$ RTV and the primary stimuli of 55\% RTV (left) and $65 \%$ RTV (right) 

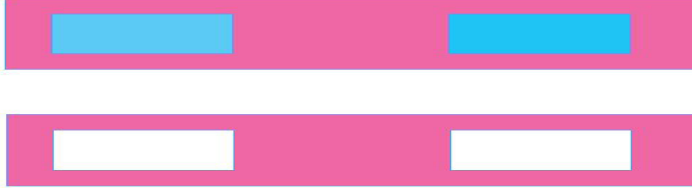

Figure 3. Test sample of the crispening effect with the secondary stimulus of $75 \%$ RTV and the primary stimuli of $55 \%$ RTV (left) and $65 \%$ RTV (right)
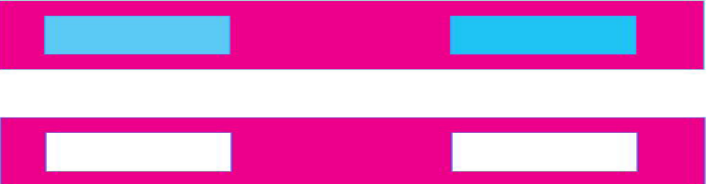

Figure 4. Test sample of the crispening effect with the secondary stimulus of $100 \%$ RTV and the primary stimuli of 55\% RTV (left) and $65 \%$ RTV (right)

Samples were constructed in the Adobe Indesign CS5 program, so that the primary stimuli had the following Lab values: field of 55\% RTV L $=77.00$ $a=-24.00$ and $b=-31$, while the values of the referential primary stimulus of $65 \%$ RTV were $\mathrm{L}=$ $73.00, a=-29.00$ and $b=-36.00$. The respondents used one of the five visual evaluation techniques, namely the technique of simultaneous binocular harmonization [13] and they had the task to try in the Indesign CS5 program to harmonize the blank field of the test primary stimulus so that it is the same or similar to the value of the field of the referential primary stimulus located above the test sample, while the backgrounds were in the corresponding values of the RTV (25\% RTV, $50 \%$ RTV, 75\% RTV and 100\% RTV) both on the referential and the test sample.

As the test was done in the Indesign CS5 program and as the limitation of the program is that the measurement of the Lab value is rounded to the integer, all values are expressed as whole numbers.

The evaluation of samples was carried out on a Lenovo G580 laptop which has a LED blacklit HD Vibrant View display, with a diagonal of 15.6 " and a resolution of $1366 \times 768$. The carried out experiment was in accordance with the ISO 3664: 2009 guidelines, meaning that the distance of the respondents from the screen was $60 \mathrm{~cm}$, the viewing angle was $10^{\circ}$, while the evaluation of the samples was carried out under the standard CIE D50 lighting. The time the respondents had on their hands was unlimited.

The evaluation of the test samples was conducted on a sample of 10 respondents (mixed female-male population, without experience in the evaluation of such tests), the average age of 31 years. Prior to the test, all respondents were subjected to a test of defective color vision to ascertain whether they were competent for this kind of research. Color vision deficiency was verified with the help of the Ishihara test which confirmed that all respondents were $100 \%$ successful in the testing.

The results of the research are presented with the help of the $\Delta \mathrm{E}_{00}$ formula.

$$
\begin{aligned}
& \Delta L^{\prime}=L_{b}^{\prime}-L_{s}^{\prime} \\
& \Delta C_{a b}^{\prime}=C_{a b, b}^{\prime}-C_{a b, s}^{\prime} \\
& \Delta H^{\prime} a b=\left[2\left(C_{a b, b}^{\prime} C_{a b, s}^{\prime}\right)^{0.5} \sin \left(\frac{\Delta h_{a b}^{\prime}}{2}\right)\right] \\
& \Delta E_{00}=\left[\left(\frac{\Delta L^{\prime}}{k_{L} S_{L}}\right)^{2}+\left(\frac{\Delta C_{a b}^{\prime}}{k_{C} S_{C}}\right)^{2}+\left(\frac{\Delta H_{a b}^{\prime}}{k_{H} S_{H}}\right)^{2}+R_{T}\left(\frac{\Delta C_{a b}^{\prime}}{k_{C} S_{C}}\right)\left(\frac{\Delta H_{a b}^{\prime}}{k_{H} S_{H}}\right)\right]^{0.5}
\end{aligned}
$$

\section{Research results and the discussion of results}

This part of the paper presents the results of the research in a way that shows how great the deviation of the $\Delta \mathrm{E}_{00}$ value of the referential sample is in relation to the test sample. After the harmonization carried out by the respondents, Lab values were measured on all test samples in the Indesign CS5 program with the help of the color picker tool, and with the $\Delta \mathrm{E}_{00}$ formula it was presented how great the deviation in color was between the referential and the test samples.

Table 1 shows all Lab values individually, for all ten respondents who harmonized the test primary stimuli with the referential primary stimuli with the value of $55 \%$ RTV on all four variations of the background - secondary stimuli with the value of $25 \%, 50 \%, 75 \%$, and $100 \%$ RTV.

The table also shows how great the deviation of the $\Delta \mathrm{E}_{00}$ value between the referential and test samples is for each individual respondent.

Table 2 shows all Lab values individually, for all ten respondents who harmonized the test primary stimuli with the referential primary stimuli with the value of $65 \%$ RTV on all four variations of the background - secondary stimuli with the value of $25 \%$ RTV, 50\% RTV, $75 \%$ RTV and $100 \%$ RTV. 
The table also shows how great the deviation of the $\Delta \mathrm{E}_{00}$ value between the referential and test samples is for each individual respondent.

In the following part of the paper, it is graphically shown (Figures 5 to 8 ) what the measured deviation of the $\Delta \mathrm{E}_{00}$ value is for all ten respondents on the primary stimulus with the value of $55 \% \mathrm{RTV}$, and it is done for each variation of the background individually.

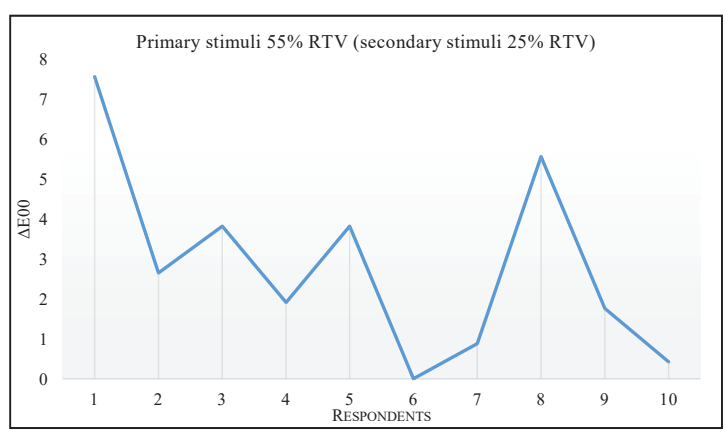

Figure 5. An overview of the deviation of $\Delta \mathrm{E}_{00}$ for each respondent on a background of $25 \%$ RTV for the primary stimulus of $55 \%$ RTV
In the above shown Figure 5, where the respondents harmonized the primary stimulus of $55 \%$ RTV, and the secondary stimulus is that of $25 \%$ RTV, it can be seen that the greatest deviation was recorded with the respondent 1 , while the smallest deviation was recorded with the respondent 6 , where basically no deviation was recorded because the respondent correctly harmonized the values of the test primary stimulus with the referential sample.

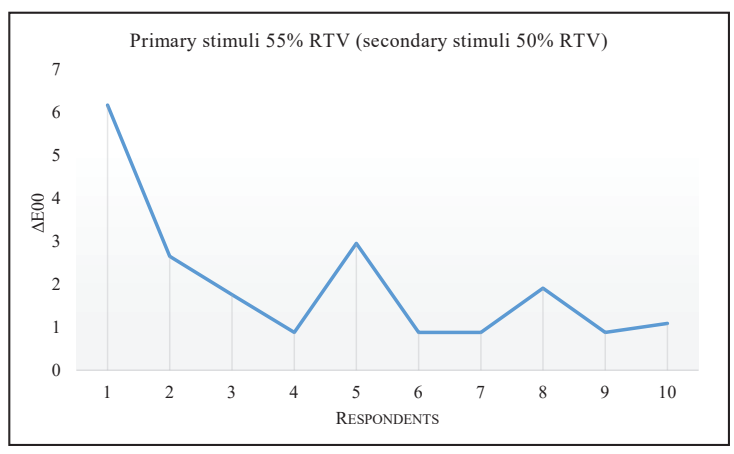

Figure 6. An overview of the deviation of $\Delta \mathrm{E}_{00}$ for each respondent on a background of $50 \%$ RTV for the primary stimulus of $55 \%$ RTV

Table 1. An overview of the assigned Lab values of test samples for the primary stimulus of 55\% RTV on all four variations of the secondary stimulus

\begin{tabular}{|c|c|c|c|c|c|c|c|c|c|c|c|c|c|c|c|c|}
\hline & \multicolumn{4}{|c|}{$25 \%$ RTV } & \multicolumn{4}{|c|}{$50 \%$ RTV } & \multicolumn{4}{|c|}{ 75\% RTV } & \multicolumn{4}{|c|}{$100 \%$ RTV } \\
\hline Respondents & $\mathbf{L}$ & $\mathbf{a}$ & $\mathbf{b}$ & $\Delta \mathrm{E}$ & $\mathbf{L}$ & $\mathbf{a}$ & b & $\Delta \mathrm{E}$ & $\mathrm{L}$ & $\mathbf{a}$ & b & $\Delta \mathrm{E}$ & $\mathbf{L}$ & $\mathbf{a}$ & b & $\Delta \mathrm{E}$ \\
\hline 1 & 85 & -16 & -21 & 7.56 & 83 & -17 & -22 & 6.17 & 78 & -22 & -29 & 1.28 & 82 & -19 & -24 & 4.82 \\
\hline 2 & 74 & -27 & -34 & 2.65 & 74 & -27 & -34 & 2.65 & 74 & -27 & -34 & 2.65 & 74 & -27 & -34 & 2.65 \\
\hline 3 & 73 & -29 & -36 & 3.82 & 75 & -26 & -33 & 1.76 & 77 & -24 & -31 & 0 & 75 & -26 & -34 & 1.91 \\
\hline 4 & 75 & -26 & -34 & 1.91 & 76 & -25 & -32 & 0.88 & 76 & -26 & -33 & 1.24 & 74 & -24 & -34 & 2.65 \\
\hline 5 & 73 & -29 & -36 & 3.82 & 74 & -28 & -35 & 2.95 & 73 & -29 & -36 & 3.82 & 73 & -29 & -36 & 3.82 \\
\hline 6 & 77 & -24 & -31 & 0 & 78 & -23 & -30 & 0.88 & 77 & -24 & -31 & 0 & 77 & -24 & -31 & 0 \\
\hline 7 & 76 & -25 & -32 & 0.88 & 76 & -25 & -32 & 0.88 & 77 & -24 & -31 & 0 & 75 & -26 & -33 & 1.76 \\
\hline 8 & 71 & -31 & -38 & 5.56 & 75 & -26 & -34 & 1.91 & 74 & -27 & -34 & 2.65 & 75 & -26 & -34 & 1.91 \\
\hline 9 & 75 & -26 & -33 & 1.76 & 76 & -25 & -32 & 0.88 & 74 & -27 & -34 & 2.65 & 77 & -24 & -31 & 0 \\
\hline 10 & 77 & -24 & -30 & 0.42 & 78 & -23 & -29 & 1.09 & 77 & -24 & -30 & 0.42 & 77 & -24 & -30 & 0.42 \\
\hline
\end{tabular}

Table 2. An overview of the assigned Lab values of test samples for the primary stimulus of $65 \%$ RTV on all four variations of the secondary stimulus

\begin{tabular}{|l|c|c|c|c|c|c|c|c|c|c|c|c|c|c|c|c|}
\hline & \multicolumn{4}{|c|}{$\mathbf{2 5 \%}$ RTV } & \multicolumn{4}{|c|}{$\mathbf{5 0 \%}$ RTV } & \multicolumn{3}{c|}{$\mathbf{7 5 \%}$ RTV } & \multicolumn{3}{c|}{$\mathbf{1 0 0} \%$ RTV } \\
\hline Respondents & $\mathbf{L}$ & $\mathbf{a}$ & $\mathbf{b}$ & $\Delta \mathrm{E}$ & $\mathbf{L}$ & $\mathbf{a}$ & $\mathbf{b}$ & $\Delta \mathrm{E}$ & $\mathbf{L}$ & $\mathbf{a}$ & $\mathbf{b}$ & $\Delta \mathrm{E}$ & $\mathbf{L}$ & $\mathbf{a}$ & $\mathbf{b}$ & $\Delta \mathrm{E}$ \\
\hline $\mathbf{1}$ & 74 & -27 & -35 & 1.11 & -78 & -23 & -30 & 4.7 & 77 & -24 & -30 & 3.97 & 76 & -25 & -32 & 2.94 \\
\hline $\mathbf{2}$ & 71 & -31 & -37 & 1.89 & 71 & -31 & -37 & 1.89 & 71 & -31 & -37 & 1.89 & 71 & -31 & -37 & 1.89 \\
\hline $\mathbf{3}$ & 69 & -33 & -41 & 3.64 & 71 & -31 & -38 & 1.76 & 73 & -29 & -36 & 0 & 71 & -31 & -38 & 1.76 \\
\hline $\mathbf{4}$ & 70 & -32 & -40 & 2.76 & 73 & -29 & -36 & 0 & 72 & -29 & -37 & 0.84 & 71 & -31 & -38 & 1.76 \\
\hline $\mathbf{5}$ & 67 & -37 & -44 & 5.77 & 69 & -34 & -42 & 3.88 & 68 & -35 & -43 & 4.76 & 67 & -36 & -44 & 5.64 \\
\hline $\mathbf{6}$ & 72 & -30 & -37 & 0.88 & 76 & -25 & -32 & 2.94 & 74 & -37 & -34 & 1.2 & 74 & -37 & -34 & 1.20 \\
\hline $\mathbf{7}$ & 73 & -28 & -35 & 0.47 & 73 & -29 & -36 & 0 & 75 & -26 & -33 & 2.06 & 73 & -28 & -35 & 0.47 \\
\hline $\mathbf{8}$ & 65 & -40 & -46 & 7.67 & 70 & -33 & -40 & 2.89 & 67 & -37 & -44 & 5.77 & 69 & -34 & -42 & 3.88 \\
\hline $\mathbf{9}$ & 67 & -37 & -44 & 2.77 & 71 & -31 & -39 & 1.89 & 72 & -30 & -37 & 0.88 & 70 & -33 & -40 & 2.89 \\
\hline $\mathbf{1 0}$ & 75 & -26 & -34 & 1.96 & 74 & -27 & -35 & 1.11 & 72 & -29 & -37 & 0.84 & 74 & -28 & -35 & 0.87 \\
\hline
\end{tabular}


In Figure 6, where the primary stimulus had the value of $55 \%$ RTV and the secondary of $50 \% \mathrm{RTV}$, it can be seen that the greatest deviation, as it was the case with the previous overview, was recorded with the respondent 1 , while the smallest deviation of the test stimulus in relation to the referential stimulus was recorded with the respondents 4, 6, 7 and 9 who had identical values.

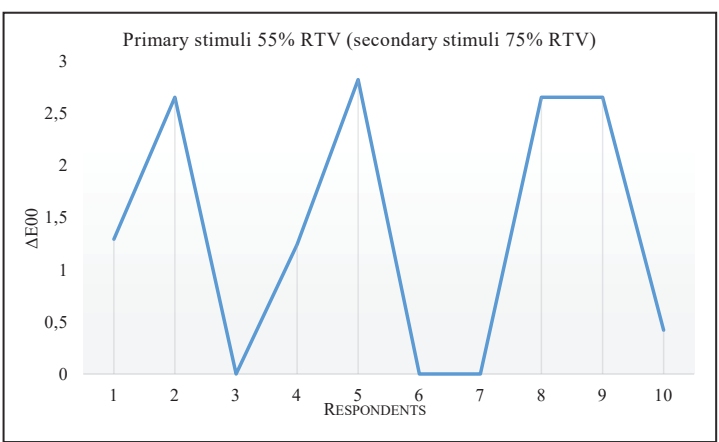

Figure 7. An overview of the deviation of $\Delta \mathrm{E}_{00}$ for each respondent on a background of $75 \%$ RTV for the primary stimulus of $55 \%$ RTV

Figure 7 shows the harmonization of the primary stimulus of $55 \%$ RTV, where the secondary stimulus had the value of $75 \%$ RTV, and it can be seen that the greatest deviation was measured with the respondent 5 , whereas the smallest deviation of the test stimulus in relation to the referential stimulus was recorded with the respondents 3, 6 and 7, where there is no deviation.

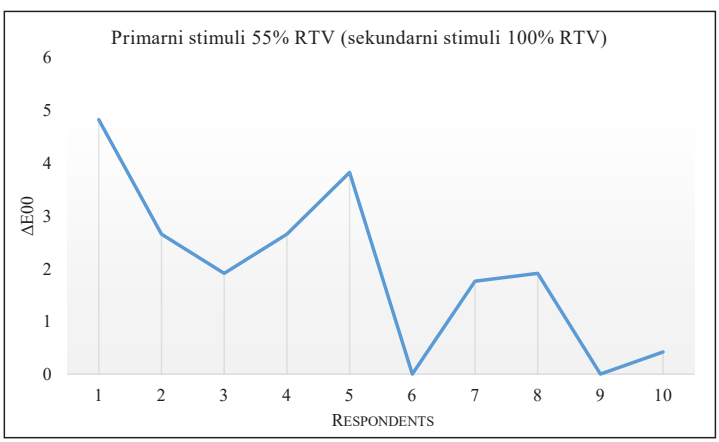

Figure 8. An overview of the deviation of $\Delta \mathrm{E}_{00}$ for each respondent on a background of $100 \%$ RTV for the primary stimulus of $55 \%$ RTV

In Figure 8, where the primary stimulus had the value of 55\% RTV and the secondary stimulus of $100 \%$ RTV, it is observed that the greatest deviation was recorded with the respondent 1 , while the smallest deviation was recorded with the respondents 6 and 9 who harmonized the test stimulus identically with the values of the referential stimulus.

In the following part of the paper, it is graphically shown (Figures 9 to 12) what the measured deviation of the $\Delta \mathrm{E}_{00}$ value is for all ten respondents on the primary stimulus with the value of $65 \% \mathrm{RTV}$, and it is done for each variation of the background individually.

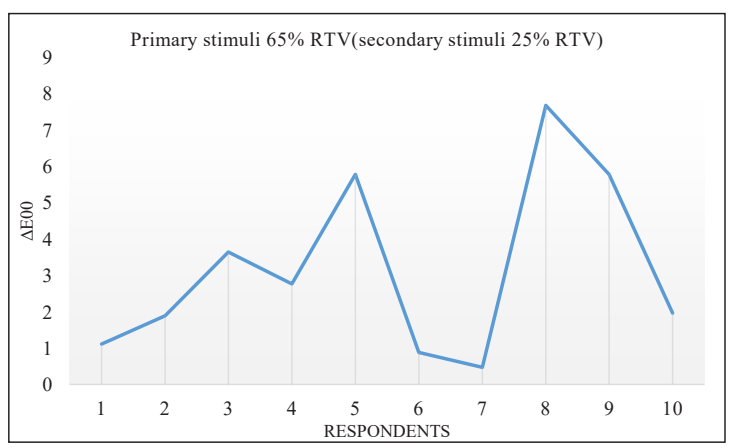

Figure 9. An overview of the deviation of $\Delta \mathrm{E}_{00}$ for each respondent on a background of $25 \%$ RTV for the primary stimulus of $65 \%$ RTV

Figure 9 shows the harmonization of the primary stimulus of $65 \%$ RTV, where the secondary stimulus had the value of $25 \% \mathrm{RTV}$, and it can be seen that the greatest deviation was recorded with the respondent 8 , while the smallest deviation was recorded with the respondent 7 .

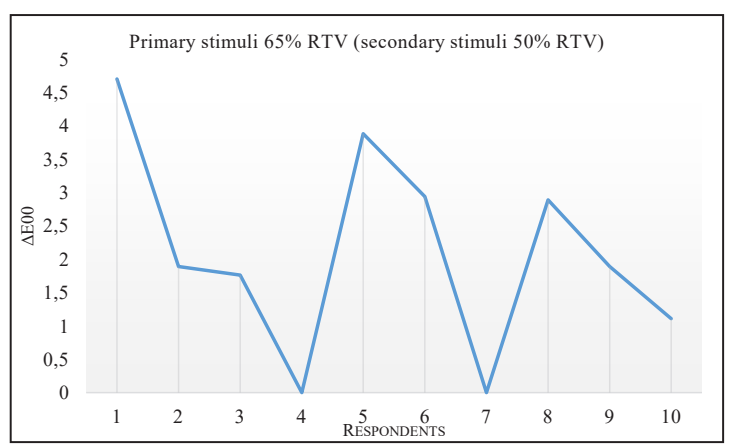

Figure 10. An overview of the deviation of $\Delta \mathrm{E}_{00}$ for each respondent on a background of $50 \%$ RTV for the primary stimulus of $65 \%$ RTV

In the above shown Figure 10, where respondents harmonized the primary stimulus of $65 \%$ RTV and the secondary stimulus had the value of $50 \%$ RTV, it can be seen that the greatest deviation was recorded with the respondent 1 , while the smallest deviation was recorded with the respondents 4 and 7 , where there is actually no deviation as they correctly harmonized the values of the test primary stimulus with the referential sample. 


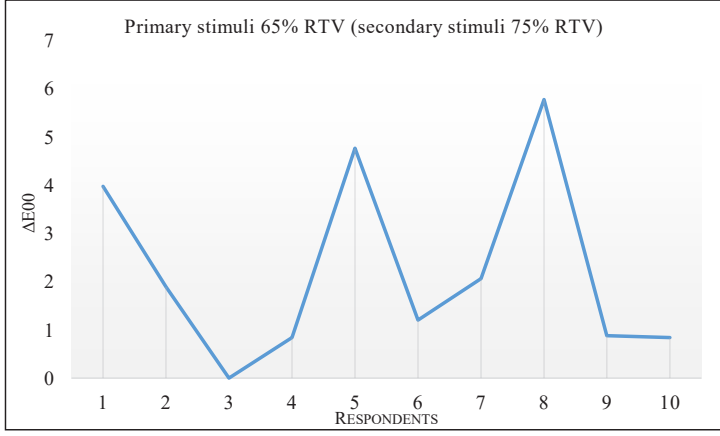

Figure 11. An overview of the deviation of $\Delta \mathrm{E}_{00}$ for each respondent on a background of $75 \%$ RTV for the primary stimulus of $65 \%$ RTV

In Figure 11, where the primary stimulus had the value of $65 \%$ RTV and the secondary stimulus of $75 \% \mathrm{RTV}$, it is observed that the greatest deviation was recorded with the respondent 8 , while the smallest deviation was recorded with the respondent 3 who harmonized the test stimulus identically as the referential stimulus.

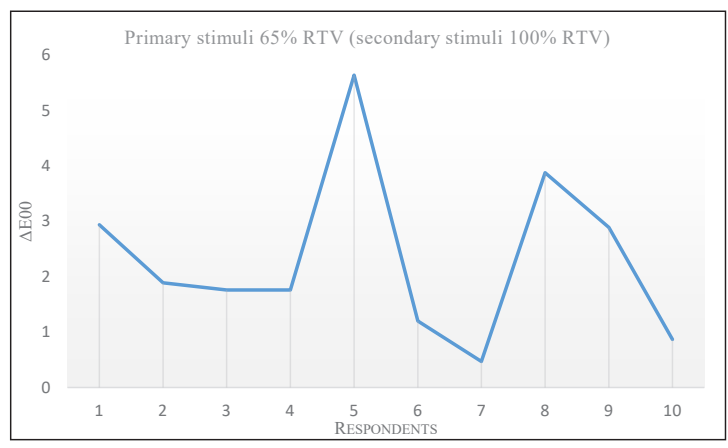

Figure 12. An overview of the deviation of $\Delta \mathrm{E}_{00}$ for each respondent on a background of $100 \%$ RTV for the primary stimulus of $65 \%$ RTV

Figure 12 shows the harmonization of the primary stimulus with the value of $65 \%$ RTV, where the secondary stimulus had the value of $100 \% \mathrm{RTV}$, and it can be observed that the greatest deviation was recorded with the respondent 5 , while the smallest deviation of the test stimulus in relation to the referential stimulus was recorded with the respondent 7 .

In the following graphs (Figures 13 to 16 ) it is shown how great the deviation of all ten respondents is for every primary stimulus with the value of $55 \%$ RTV and $65 \%$ RTV on all four variations of the secondary stimuli.

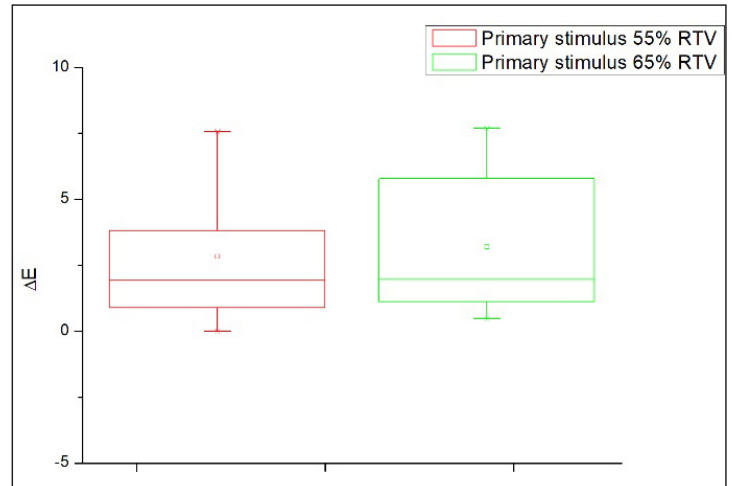

Figure 13. An overview of the measured values of $\Delta \mathrm{E}_{00}$ for all respondents for the primary stimuli with the value of $55 \%$ RTV and $65 \%$ RTV on a background of $25 \%$ RTV

In Figure 13, the ratio of the comparison of the test primary stimuli of $55 \%$ RTV and $65 \%$ RTV for all ten respondents on a background of $25 \%$ RTV can be seen. It can be observed from the Figure that the respondents had nearly identical results in the harmonization of the primary stimuli of 55\% RTV and 65\% RTV. Namely, the sum of the $\Delta \mathrm{E}_{00}$ value for the test primary stimulus of $55 \% \mathrm{RTV}$ is 28.38 , while the sum of the $\Delta \mathrm{E}_{00}$ value for the test primary stimulus of $65 \%$ $\mathrm{RTV}$ is 28.92 .

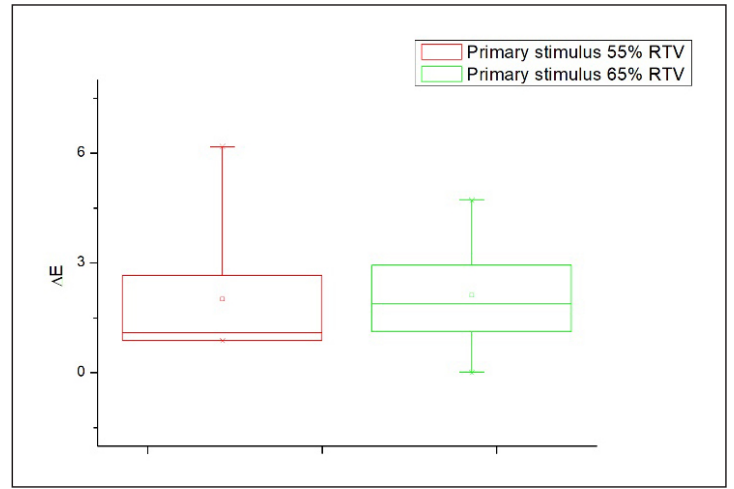

Figure 14. An overview of the measured values of $\Delta \mathrm{E}_{00}$ for all respondents for the primary stimuli with the value of $55 \%$ RTV and $65 \%$ RTV on a background of $50 \%$ RTV

In Figure 14, the ratio of the comparison of the test primary stimuli of 55\% RTV and $65 \%$ RTV for all ten respondents on a background of $50 \%$ RTV can be seen. It can be observed from the Figure that the respondents had very similar results in the harmonization of the primary stimuli of 55\% RTV and 65\% RTV. Namely, the sum of the $\Delta \mathrm{E}_{00}$ value for the primary stimulus of $55 \%$ RTV is 20.05 , while the sum of the $\Delta \mathrm{E}_{00}$ value for the primary stimulus of $65 \% \mathrm{RTV}$ is 
21.06. It can be observed that during the harmonization of the test primary stimulus of $65 \%$ RTV, the respondents showed slightly higher oscillations than during the harmonization of the test primary stimulus of 55\% RTV, except for the respondent 1 , who showed the greatest extreme with the test primary stimulus of 55\% RTV.

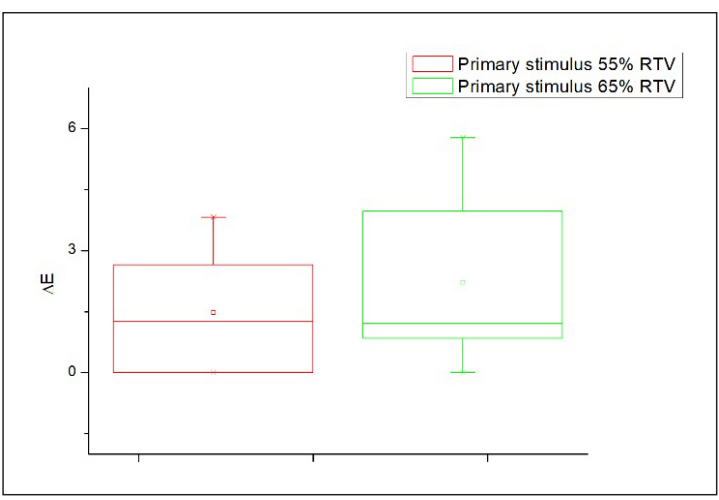

Figure 15. An overview of the measured values of $\Delta \mathrm{E}_{00}$ for all respondents for the primary stimuli with the value of $55 \%$ RTV and $65 \%$ RTV on a background of $75 \%$ RTV

In Figure 15, the ratio of the comparison of the test primary stimuli of 55\% RTV and 65\% RTV for all ten respondents on a background of 75\% RTV can be seen. It can be observed from the Figure that the respondents had significantly better results in the harmonization of the primary stimuli of 55\% RTV in relation to the primary stimuli of $65 \%$ RTV. Namely, the sum of the $\Delta \mathrm{E}_{00}$ value for the test primary stimulus of $55 \% \mathrm{RTV}$ is 14.71 , while the sum of the $\Delta \mathrm{E}_{00}$ value for the test primary stimulus of $65 \%$ RTV is 22.21 .

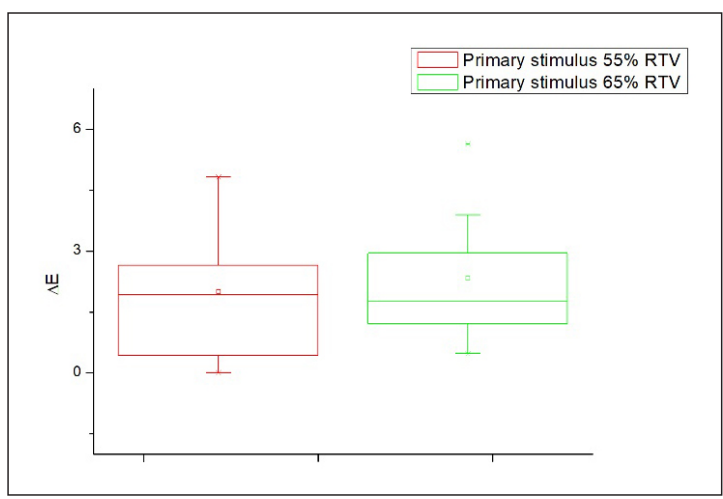

Figure 16. An overview of the measured values of $\Delta \mathrm{E}_{00}$ for all respondents for the primary stimuli with the value of $55 \%$ RTV and $65 \%$ RTV on a background of $100 \%$ RTV
Figure 16 shows the ratio of the comparison of the test primary stimuli of 55\% RTV and 65\% RTV for all ten respondents on a background of $100 \%$ RTV. It can be observed from the Figure that the respondents had lower oscillations in the harmonization of the primary stimuli of $65 \%$ RTV in relation to the primary stimuli of $55 \%$ RTV. However, it can also be observed that during the harmonization of the test primary stimulus of $55 \%$ RTV, the respondents were closer to the required values of the referential primary stimulus of the same value. Namely, the sum of the $\Delta \mathrm{E}_{00}$ value for the test primary stimulus of $55 \%$ RTV is 19.94, while the sum of the $\Delta \mathrm{E}_{00}$ value for the test primary stimulus of $65 \% \mathrm{RTV}$ is 23.30 .

\section{Conclusion}

Any manifestation of background psychophysical visual effects is undesirable in any form. The greatest distortion in color perception occurs in background effects with a certain combination of complementary color pairs. In this case, it was a combination where the primary stimulus was in the blue-green color and the secondary stimulus in the purple color. The vast majority of respondents had a problem in harmonizing the colors of the test primary stimuli with the colors of the referential primary stimuli precisely because of the change in the intensity of the background color that varied.

Overall, considering the results of all ten respondents, there is a smaller difference in the deviation between the referential and the test stimulus on the samples where the primary stimulus has the value of 55\% RTV compared to the primary stimulus of $65 \%$ RTV on all values of background variations.

The respondents showed the smallest difference in the case of the primary stimulus with the value of $55 \%$ RTV on a background of $75 \%$ RTV, while the greatest difference was observed in the case of the primary stimulus with the value of $65 \%$ RTV on a background of $25 \%$ RTV.

Recommendations for designers when creating conceptual solutions that contain a color combination as was the one in this research would be to avoid, if possible, using complementary pairs of colors in a geometric form that was used in this research. If the customer requires using the combination of the purple color as a 
The influence of the chromatic effect of crispening on the shift in the manifestation of the color of the observer

secondary stimulus and the blue-green color as the primary stimulus, it is best to use the values of the color ratio that were shown in this paper to have the smallest shift in the manifestation of color on the perception of the observer.

\section{References}

1. Hajdek, K. Budimir,I. Krizmanić, K. 2016. The appearance of the visual effect simultaneous contrast depending on the printing substrate. // Acta graphica. Vol. 27, 3, pp. 7-14.

2. Hajdek, K. Budimir, I. Vusić, D. 2016. The intensity of the simultaneous contrast effect depending on the change of background lightness. // Tehnički vjesnik : znanstveno-stručni časopis tehničkih fakulteta Sveučilišta u Osijeku. Vol. 23, 2, pp. 525-531.

3. Vusić, D. Geček, R. Hajdek, K. 2016. Color appearance of the neon color spreading effect. // Acta graphica. Vol. 27, 2, pp. 7-13.

4. Adelson, E. H. 1993. Perceptual Organization and the Judgment of Brightness. // Science. Vol. 262, 5142, pp. $2042-2044$.

5. Hajdek, K. Budimir, I. Mrvac, N. 2017. The intensity of the background visual effect of crispening depending on background lightness. //Tehnički vjesnik : znanstveno-stručni časopis tehničkih fakulteta Sveučilišta u Osijeku. Vol.24, 5, pp. 1571-1578.
6. Takasaki, H. 1966. Lightness change of gray induced by change in reflectance of gray background. // Journal of the Optical Society of America. Vol. 56, 4, pp. 504-509.

7. Takasaki, H. 1967. Chromatic Changes Induced by Changes in Chromaticity of Background of Constant Lightness. // Josa. Vol. 57, 1, pp. 93-96.

8. Semmelroth, C. C. 1970. Prediction of Lightness and Brightness on Different Backgrounds. // Josa- Vol. 60, 12, pp. 1685-1689.

9. Karimipour, H. Kandi, S. G. 2017. Performance of advanced color difference and CAM02-based formulas in prediction of the Crispening effect for reflective samples. // Color research and application. Vol. 42, 5, pp. 542-551.

10. Kane, D. Bertalmio, M. 2016. The influence of lightness, and the crispening effect on the perceived contrast of textured images. IS\&T International Symposium on Electronic Imaging Science and Technology; 2016 Febr. Pp. 14-18. San Francisco (CA,USA)

11. Xin, J. H. Lam, C. C. Luo M. R. 2004. Evaluation of the crispening effect using CRT-displayed colour samples. // Color research and application. Vol. 29, 5, pp, 374-380.

12. Ho, K. M. R.; Cui, G.; Luo, M. R.; Rigg, B. 2002. A Lightness Difference Formula for Predicting Crispening Effects. Color and Imaging Conference, 10th Color and Imaging Conference, Scottsdale, Arizona, USA. pp, 161-165.

13. Milković, M. Mrvac, N. Vusić, D. 2009. Vizualna psihofizika i dizajn. Veleučilište u Varaždinu, Varaždin, Hrvatska. 